\title{
US teams join hands to build dexterous robots
}

\section{CAMBRIDGE, MASSACHUSETTS}

After years of following increasingly isolated paths, robotics researchers in the United States have agreed on a common goal: making machines that are good with their hands. They hope that a unified scientific front will help them to compete against groups in Asia, where research into humanoid robots has been heavily funded while cash for US projects has dwindled.

At the first annual 'Robotics: science and systems' conference, held at the Massachusetts Institute of Technology (MIT) in Cambridge last week, delegates embraced the idea of pooling their resources.

“A bunch of people realized what we're all doing fits together - this is a field," says Oliver Brock, co-director of the Laboratory for Perceptual Robotics at the University of Massachusetts, Amherst. "We're bringing together the engineering and science to automate the performance of physical work."

And in March, a group of robotics experts meeting in Houston, Texas, agreed that US researchers should work together to develop robots that can move around and do useful work: a field called autonomous mobile manipulation (AMM). This made more sense than trying to compete individually with the strengths of foreign groups, such as the twolegged walking robots being developed in Japan and Korea, they decided. A four-year,

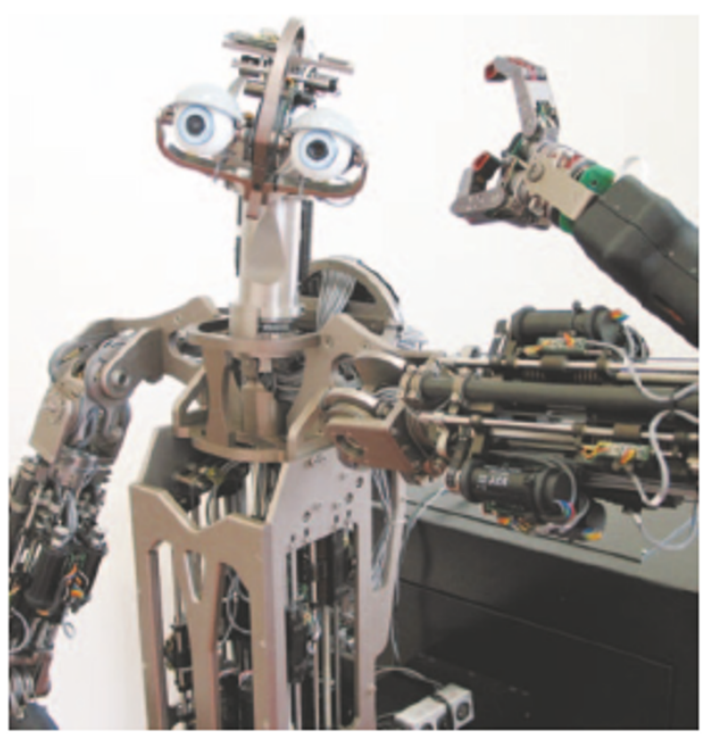

Handy device: Domo is able to track and grasp balls.

\$14-million NASA initiative to support AMM was launched this spring.

AMM could revolutionize areas such as manufacturing, agriculture and space applications, adds Rodney Brooks, director of MIT's Computer Science and Artificial Intelligence Laboratory. ${ }^{\alpha}$ There's plenty of reason to believe that robot manipulation will change the world.

To make his point, he unveiled one of the most advanced projects at the conference: a robot called Domo. Built by $\mathrm{PhD}$ student Aaron
Edsinger-Gonzales and research engineer Jeff Weber, Domo combines computer vision, force-controlled movements and tactile sensing. So far, it can track the motion of a coloured ball and reach out with one or both hands to grasp it. Brooks hopes that it will learn to feel its way around and be able to manipulate objects with the dexterity of a six-year-old child.

But not everyone is happy. One reason for building robots that can do specific tasks, such as using hand tools, is to learn more about the underlying principles of those actions in humans. Some researchers worry that the AMM approach will favour technological advances at the expense of basic research. "There's no science yet," one MIT researcher not involved in the project says of Doma. "But it's a sweet robot."

The fear of falling behind foreign competitors is likely to keep US researchers working towards a common technological goal. Companies such as Toyota, Honda and Sony all have major programmes to develop humanoid robots, for example, and Japan reportedly plans to invest billions of dollars in the field over the next five years.

"They'll have all the patents," says Alan Peters, a robotics expert at Vanderbilt University in Nashville, Tennessee. "It will be as if the transistor were invented in Japan, and Bill Gates was named Kobayashi."

Gregory Huang

\section{Whaling divisions deepen as Japan pushes for credibility}

\section{TOKYO}

The annual meeting of the International Whaling Commission (IWC) this month is set to take a different tone from previous gatherings. For the first time, the prowhaling lobby seems to have amassed sufficient numbers to exercise a majority.

The IWC has long struggled to balance the competing demands of its remit to conserve whale stocks and develop a sustainable whaling industry. Its membership has been bitterly divided since 1986 , when the commission introduced a moratorium on commercial whaling.

The pro-whaling block, led by Japan, has rarely got its way. The commission acts more like a conservation organization than one geared towards regulating commercial whaling, complains Joji Morishita of Japan's fishery agency. He says that, with a majority, the pro-whaling nations would steer the IWC back towards its original purpose.

The pro-whaling lobbydoes not yet have enough members to quash the moratorium on commercial whaling, which would require a three-quarters majority. But it may be able to push the IWC to axe several subcommittees, such as those devoted to conservation or the impact of whaling on whale-watching, says Phillip Clapham, a marine biologist at the National Marine Mammal Laboratory in Seattle.

It could also help Japan to score some much needed political credibility points. Since the moratorium, Japan has killed more than 8,000 whales for scientific research. This is permitted under IWC rules, although Japan's programme has never been approved by the commission. At the IWC's annual meeting in Ulsan, South Korea, on 20-24 June, Japan is expected to table a proposal that would double its annual take for research purposes.

But anti-whaling nations believe the programmes have little scientific benefit. Although Japan doesn't need IWC backing to carry out scientific whaling, formal approval for either its previous programme or its latest proposals would bolster the country's image (see pages 856 and 883).

Morishita says that the extra catch will provide data that anti-whalers say are needed before commercial whaling can resume. "As it gets more political, the scientists come up with more difficult questions, and these require more data," he says.

David Cyranoski 